This is a pre-copyedited, author-produced version of an article accepted for publication in Applied Linguistics following peer review. The version of record Scheffler, P. 2012.

'Theories Pass. Learners and Teachers Remain' Applied Linguistics 33/5: 603-607 is available online at: https://academic.oup.com/applij/article-abstract/33/5/603/171100/Theories-passLearners-and-Teachers-Remain?redirectedFrom=fulltext

\title{
Theories Pass. Learners and Teachers Remain.
}

The challenge facing foreign language (FL) learners and their teachers is enormous. To become successful, learners need to have at their disposal thousands of lexical items and chunks. They need to know what meanings and grammatical functions these items express, how to produce and how to combine them. They need to know when it is appropriate to use particular items and when it is not. They often need to apply all this information with little or no time for conscious reflection. And they need to master it in a fraction of the time available to first language learners.

To make matters worse, for a long time learners were supposedly done a disservice by the very people that were supposed to be helping them, namely, teachers. As Long and Robinson (1998: 20) say, virtually all traditional FL instruction, labelled by them as 'focus on forms', was wrong. Given that traditional teaching resulted in very few FL learners becoming 'finishers', it follows that 'grammatical syllabi, linguistically "simplified" teaching materials, explicit grammar explanations, immediate forced student production, pattern practice, translation, error "correction", should be 'associated with failure' and that successful learners probably learnt 'through them or in spite of them, not necessarily because of them'.

In the second half of the 20th century the field of SLA research came into existence. The findings produced by the people involved should have discredited these "neanderthal teaching practices (Long 1988: 136) in the eyes of the teachers. The teachers should have embraced and implemented the recommendations coming from SLA researchers. That is, they should have stopped providing learners with explicit explanations of how a foreign language works and instead should have converted to 'focus on form', i.e. comprehensible input, negotiation for meaning and implicit feedback.

Yet, in many foreign language contexts that did not happen (Pawlak 2007). Many teachers kept teaching to the structural syllabus, taught grammar explicitly and used their learners' L1 to make meaning clear. A possible explanation for this state of affairs is provided by Skehan (1998: 94), who describes teachers as 'a conservative profession, out of touch with language acquisition studies'. So, basically, teachers stuck to methods which were familiar and easy to apply, and they were unwilling to become engaged with SLA research (cf. Borg 2010).

But do these teachers teach the way they do because they are lazy and unprofessional? Not necessarily. As for example Swan (2005: 386-387) and Butzkamm and Caldwell (2009: 242) point out, the history of foreign language teaching is not a 'succession of failed methods'. On the contrary, countless competent FL users have been produced by traditional teaching, which means that the very techniques condemned by SLA specialists seem to have worked for many learners and teachers.

So how is it possible that teaching procedures which do not fit an established SLA theory are, at least in some contexts, effective? Perhaps Long and Robinson (1998) are right after all whey they say that successful learners learn in spite of them rather than because of them? We can only answer this question if we subject these procedures to rigorous empirical scrutiny and compare their effectiveness with the effectiveness of the techniques advocated on the basis of the latest SLA research findings. An important goal of SLA theory is to explain 
how learning is accomplished through teaching. No teaching procedure claimed by teachers to be effective should be disregarded, even if the focus of current theory is on something completely different.

As evidenced by recent surveys of the field (e.g. Ellis 2008), the amount of research that has been done in Second Language Acquisition in the past few decades is impressive. Comparative work on explicit and implicit instruction has also been undertaken (Norris and Ortega 2000). Yet, some of the more traditional techniques used in teaching (e.g. translation) have attracted surprisingly little attention of SLA researchers (Butzkamm and Caldwell 2009, Cook 2010). Also, as Sheen (2005: 286) and Pawlak (2007: 170) say, there is a dearth of comparative research directly involving focus on forms and focus on form in real classrooms. However, when these two instructional approaches are researched and compared, it turns out that the former is more effective than the latter. Further, there is some evidence that explicit teaching can actually affect learners' performance in unplanned language use. Let us very briefly consider three relevant examples.

The first study is Housen, Pierrard and Van Daele (2005). It is not a comparative study of the two types of focus, but it produced one finding relevant to the present discussion: explicit grammar instruction concerning French passive sentences and negation leads to improvements in unplanned oral FL performance. Second, Sheen (2005) demonstrates that pupils explicitly taught the rules of English question formation and adverb placement in addition to communicative activities do significantly better with respect to these features in oral interviews than those who are just involved in communication supported by corrective feedback. Third, Pawlak (2007) shows that pupils subjected to the traditional PPP type of instruction in English conditional sentences exhibit significant gains on a meaning-oriented dictogloss task.

It seems, then, that providing explicit grammar explanations to learners may not be a 'neanderthal' teaching practice after all. Further, there is growing empirical evidence that contrastive L1 - L2 explicit information may be necessary if FL learners are to master certain difficult L2 structures. One study from the late 1990s and one very recent study will serve as examples.

Kupferberg (1999) examined the acquisition of the perfect aspect by advanced Hebrew university learners of English. English and Hebrew differ in their marking of aspect: in the former, a verbal complex with an auxiliary verb may be used, whereas in the latter lexical means are employed. This difference caused difficulty for the subjects in the study: they were able to recognize the past perfect construction in an English text, but generally avoided it in production. In order to test the effect of contrastive metalinguistic input (CMI) on production, the subjects were divided into two groups: the experimental group, which received CMI, and the control group, which was provided with L2 focused explicit instruction. The effects of the treatments were measured by means of written story-telling tasks which created natural contexts for the use of the past perfect. Both groups exhibited significant gains in the number of the past perfect forms produced, but the gains of the experimental group were significantly higher that those of the control group.

Ammar, Lightbown and Spada (2010) studied French learners of English in a communicative program at an elementary school in Canada. The research questions concerned the pupils' ability to judge and form questions in English, their awareness of differences between French and English grammar in this area, and the relationship between the pupils' performance and awareness. The authors used three tasks: a grammaticality judgement task, a scrambled questions task and an interview. The first two tasks provided input for the interview, which was supposed to provide the researchers with data concerning the pupils' explicit knowledge about question formation in French and English. 
The findings were as follows. First, the pupils' judgements of grammaticality and the questions that they formed revealed their reliance on rules of French grammar. Second, few learners were able to verbalize the rules, and third, there was a positive correlation between making correct judgements and forming correct questions and awareness of L1-L2 contrasts. The authors offer the following conclusion concerning the usefulness of contrastive L1-L2 information: 'it would appear that there is crucial information students need to know and that this information may best be provided through explicit instruction' (p. 142-143).

If there was anything more 'neanderthalian' than explicit explanations of discrete grammar points, then it must have been translation. Since the Reform Movement in the second half of 19th century, translation as a means of making meaning clear has been discouraged, and translation of disconnected sentences and texts has been generally condemned by FL teaching specialists (cf. Fotos 2005). It has also been ignored by most SLA researchers (Cook 2010: 21). There are signs, though, that even this long-time exile from SLA research may be finally allowed to make a come-back. The books published recently by Butzkamm and Caldwell (2009) and Cook (2010) are indications that translation is a topic worth researching and that teachers who resisted the ban on its use in the classroom may have known what they were doing. A very recent report from one of such teachers is Kim's (2011) study. Frustrated by her college students' inability to improve the quality of their writing during the drafting process, Kim decided to ask them to translate their compositions into their native language, i.e. Korean. The translation exercise, with which they were familiar from their high school instruction, proved to be an eye opener for them: they were able to see the problems they had both in terms of form and content. Kim (2011: 160) concludes 'that an approach based on grammar-translation can be a useful means to achieve a communicative goal'.

SLA research is often undertaken with a view to improving the quality of FL teaching. As Butzkamm and Caldwell (2009: 242) observe, however, it is often undertaken by people 'who have never been full time teachers in public schools and taught across the ability range for at least a couple of years'. Further, it is undertaken by people who are often very dismissive of the opinions of those who on the basis of their experience maintain that 'neanderthal teaching' often actually works. 'Let us try to understand not only what made it fail in some classrooms but also what made it tick in other contexts, and we'll make some progress' (Butzkamm and Caldwell 2009: 242).

Researchers in any area should not only remember that their theories may one day pass. They should also be prepared to forget things they are surest of, as Jean Rostand (1962: 88) also said.

\section{References}

Ammar, A., P.M. Lightbown and N. Spada 2010. 'Awareness of L1/L2 differences: does it matter?' Language Awareness 19/2: 129-146.

Borg, S. 2010. 'Language teacher research engagement.' Language Teaching 43/4: 391-429.

Butzkamm, W. and J.A.W. Caldwell 2009. The Bilingual Reform: A Paradigm Shift in Foreign Language Teaching. Tübingen: Gunter Narr Verlag.

Cook, G. 2010. Translation in Language Teaching. Oxford: Oxford University Press.

Ellis, R. 2008. The Study of Second Language Acquisition.(2nd edition) Oxford: Oxford University Press.

Fotos, S. 2005. 'Traditional and grammar translation methods for second language teaching' in Hinkel E. (ed.): Handbook of Research in Second Language Teaching and Learning. Mahwah, NJ: Lawrence Erlbaum. 
Housen, A, and M. Pierrard 2005. Investigations in instructed second language acquisition. Berlin / New York: Mouton de Gruyter.

Housen, A., M. Pierrard, and S. Van Daele 2005. 'Structure complexity and the efficacy of explicit grammar instruction' in Housen and Pierrard (eds.).

Kim, E.Y. 2011. 'Using translation exercises in the communicative writing classroom.' English Language Teaching Journal 65/2: 154-60.

Kupferberg, I. 1999. 'The cognitive turn of contrastive analysis: Empirical evidence. Language Awareness.' 8/3-4: 210-222.

Long, M.H. 1988. 'Instructed interlanguage development' in Beebe L. (ed.): Issues in Second Language Acquisition: Multiple Perspectives. New York: Newbury House.

Long, M. H. and P. Robinson 1998. 'Focus on form. Theory, research and practice' in Doughty C.J. and J. Williams (eds.): Focus on Form in Classroom Second Language Acquisition. Cambridge: Cambridge University Press.

Norris, J. M. and L. Ortega 2000. 'Effectiveness of L2 instruction: a research synthesis and quantitative meta-analysis.' Language Learning 50/3: 417-528.

Pawlak, M. 2007. 'Comparing the effect of focus on form and focus on forms in teaching English third conditional' in Pawlak (ed.): Exploring Focus on Form in Language Teaching . Kalisz - Poznan: Faculty of Pedagogy and Fine Arts.

Rostand, J. 1962. The Substance of Man. Garden City, N.Y.: Doubleday.

Sheen, R. 2005. 'Focus on formS as a means of improving accurate oral production' in Housen and Pierrard (eds.).

Skehan, P. 1998. A Cognitive Approach to Language Learning. Oxford: Oxford University Press.

Swan, M. 2005. 'Legislation by hypothesis: The case of task-based instruction.' Applied Linguistics 26/3: 376-401. 